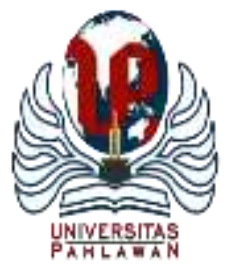

Edukatif : Jurnal Ilmu Pendidikan Volume 3 Nomor 6 Tahun 2021 Halm 4083 - 4093

EDUKATIF: JURNAL ILMU PENDIDIKAN

Research \& Learning in Education

https://edukatif.org/index.php/edukatif/index

\title{
Deskripsi Sistem Divisi Jurusan Antara Sekolah Indonesia dan Sekolah Menengah Kebangsaan Malaysia
}

\author{
Zakirman $^{1 凶}$, Wienda Gusta ${ }^{2}$, Chichi Rahayu ${ }^{3}$ \\ Universitas Terbuka, Indonesia ${ }^{1}$ \\ Universitas Putra Indonesia YPTK Padang, Indonesia ${ }^{2}$ \\ Universitas Ekasakti, Indonesia ${ }^{3}$ \\ E-mail : zakirman.official@ecampus.ut.ac.id ${ }^{1}, \underline{\text { wienda84@yahoo.com }}^{2}, \underline{\text { rahayuchichi@ gmail.com }}^{3}$
}

\begin{abstract}
Abstrak
Penelitian ini bertujuan untuk mendeskripsikan perbandingan sistem distribusi departemen di sekolah menengah di Indonesia dan Malaysia. Jenis penelitian ini adalah deskriptif, instrumen penelitian yang digunakan adalah lembar observasi dan dokumentasi dokumen saat melakukan kunjungan lapangan ke sekolah sampel di Indonesia dan Malaysia. Kesimpulan dari hasil penelitian ini antara lain perbedaan sistem pembagian jurusan dengan perbedaan yang mencolok yaitu di Indonesia sekolah dapat mengelompokkan siswa berdasarkan jurusan pada jenjang kelas X, sedangkan di Malaysia pengelompokan jurusan dimulai pada kelas 4 pada jenjang sekolah menengah. Selain itu, perbedaan dasar kurikulum yang harus ditempuh siswa juga dapat terlihat jelas dan berbeda secara signifikan.
\end{abstract}

Kata Kunci: Pembagian Jurusan, Sekolah, Indonesia, Malaysia

Abstract

This study aims to describe the comparison of departmental distribution systems in secondary schools in Indonesia and Malaysia. This type of research is descriptive, the research instrument used is the observation sheet and document documentation when conducting field visits to sample schools in Indonesia and Malaysia. Conclusions from the results of this study include differences in departmental distribution systems with striking differences, namely in Indonesia schools can classify students based on majors at grade X level, while in Malaysia, grouping majors starts at grade 4 at the secondary school level. In addition, the basic curriculum differences that students must take also can be clearly seen and differ significantly.

Kata Kunci: Division of Departments, Schools, Indonesia, Malaysia

Copyright (c) 2021 Zakirman, Wienda Gusta, Chichi Rahayu

$\triangle$ Corresponding author:

Email : zakirman.official@ecampus.ut.ac.id

DOI : https://doi.org/10.31004/edukatif.v3i6.1231

ISSN 2656-8063 (Media Cetak)

ISSN 2656-8071 (Media Online)

Edukatif : Jurnal Ilmu Pendidikan Vol 3 No 6 Tahun 2021 p-ISSN 2656-8063 e-ISSN 2656-8071 
4084 Deskripsi Sistem Divisi Jurusan Antara Sekolah Indonesia dan Sekolah Menengah Kebangsaan Malaysia-Zakirman, Wienda Gusta, Chichi Rahayu

DOI: https://doi.org/10.31004/edukatif.v3i6.1231

\section{PENDAHULUAN}

Pendidikan merupakan upaya sadar dan terencana yang dapat dilakukan oleh seseorang untuk mendapatkan perubahan yang lebih baik untuk masa depannya. Perubahan pola pikir, keterampilan dan keahlian merupakan salah satu dampak langsung yang dapat ditimbulkan jika seseorang telah menempuh jalur pendidikan (Neville, 2018). Pendidikan pada dasarnya merupakan pilar penting yang dapat mengubah dan meningkatkan kualitas sumber daya manusia di suatu negara. Dengan fokus yang tinggi pada pembangunan sektor pendidikan, maka harus dibarengi dengan peningkatan kekuatan negara tersebut, dengan kata lain negara tersebut akan menjadi milik negara maju (Arokiasamy, 2012).

Tujuan utama pendidikan adalah bagaimana menanamkan suatu keterampilan yang harus dimiliki oleh setiap siswa pada setiap jenjang dan jenjang kelas. Dalam Undang-undang No. 20 Tahun 2003 tentang Sistem Pendidikan Nasional (UUSPN) Pasal 18, menyatakan bahwa pendidikan menengah diselenggarakan untuk melanjutkan dan meluaskan pendidikan dasar serta menyiapkan peserta didiknya menjadi anggota masyarakat yang memiliki kemampuan mengadakan hubungan timbal balik dengan hubungan sosial, budaya dan alam sekitar serta dapat mengembangkan kemampuan lebih lanjut dalam dunia kerja atau pendidikan tinggi (Munirah, 2015). Namun terlihat menduanya orientasi tujuan yang ditetapkan untuk pendidikan menengah. Satu sisi menyiapkan peserta didik untuk mengikuti pendidikan umum, tetapi di sisi lain meyiapkan peserta didik untuk memasuki lapangan kerja (pendidikan spesialisasi). Perdebatan semakin tajam, ketika timbul pertanyaan apakah pendidikan menengah perlu memberikan kedua-duanya baik pendidikan umum ataupun kejuruan/spesialis dalam satu program, ataupun kedua-duanya dilaksanakan sendiri-sendiri dan terpisah (Andayani, 2012).

Sesuai kurikulum yang berlaku di seluruh Indonesia, calon siswa SMA/SMK yang akan mendaftar sekolah akan mengalami pemilihan jurusan (penjurusan). Untuk itu, calon siswa diharapkan mampu untuk menilai minat, bakat serta kemampuannya agar tidak salah memilih jurusan yang akan diambilnya. Pemilihan jurusan bagi calon siswa SMA/SMK adalah awal dari pemilihan karir ke depannya (Rahmayu \& Serli, 2018). Sistem penjurusan merupakan suatu proses penyeleksian siswa dalam menentukan jurusan. Dalam upaya penjurusan ini siswa dapat memilih program studi yang akan diikuti siswa. Penjurusan dilakukan berdasarkan atas kemampuan akademik siswa dan potensi siswa (tes IQ) (Rusdiansyah, 2017). Terdapat tiga jurusan program pada SMA yaitu program Ilmu Pengetahuan Alam (IPA), program Ilmu Pengetahuan Sosial (IPS), dan program Bahasa (BHS).

Jurusan Ilmu Pengetahuan Alam di SMA merupakan jurusan dengan mata pelajaran peminatan terdiri dari Matematika, Fisika, Kimia, dan Biologi. IPA atau yang biasa kita kenal dengan ilmu pengetahuan alam umumnya mempelajari tentang sesuatu yang berkaitan dengan makhluk hidup mulai dari manusia, hewan dan tumbuhan (Eliyarti, Rahayu, \& Zakirman, 2020). Jurusan IPS di SMA adalah sebuah wadah bagi mereka yang tertarik dan ingin mempelajari tentang hubungan antar manusia dan hubungan antara manusia dengan lingkungannya serta berbagai aspek sosial lainnya melalui berbagai mapelnya. Jurusan bahasa di SMA mempelajari yang berkaitan dengan ilmu kebahasaan baik dari segi bentuk bahasa, unsur bahasa, dan sampai budaya terbentuknya sebuah bahasa. IBB terdiri dari sejumlah mata pelajaran yaitu bahasa Indonesia, bahasa Inggris, bahasa asing lain (tergantung ketersediaan tenaga guru) dan antropologi (Putranto, Salamah, \& Wiharto, 2012). Penjurusan siswa SMA merupakan salah satu upaya untuk mengarahkan siswa berdasarkan kemampuan akademik dan minat siswa.

Sekolah Menengah Kejuruan merupakan lembaga pendidikan yang berorientasi pada pembentukan kecakapan hidup, yaitu melatih peserta didik untuk menguasai keterampilan yang dibutuhkan oleh dunia kerja terutama bisnis dan industri, memberikan pendidikan tentang wirausahaan, serta membentuk kecakapan hidup (Hayurika \& Arief, 2020). Orientasi Sekolah Menengah Kejuruan diantaranya: (1)membekali kompetensi/ketrampilan siswa untuk memenuhi kebutuhan pasar kerja di dunia usaha/dunia industry, (2) 
4085 Deskripsi Sistem Divisi Jurusan Antara Sekolah Indonesia dan Sekolah Menengah Kebangsaan Malaysia-Zakirman, Wienda Gusta, Chichi Rahayu

DOI: https://doi.org/10.31004/edukatif.v3i6.1231

membekali kompetensi/ketrampilan siswa untuk hidup mandiri mengembangkan wirausaha, menciptakan lapangan kerja, (3) membekali kompetensi/ketrampilan dan kecakapan akademis siswa untuk memberikan peluang melanjutkan ke tingkat pendidikan yang lebih tinggi. Preferensi bersekolah adalah keinginan atau kecenderungan seseorang untuk bersekolah atau tidak bersekolah di suatu sekolah yang dipengaruhi oleh faktor-faktor tertentu. Preferensi masyarakat dalam memilih sekolah sangat bervariasi, karena setiap individu mempunyai keinginan berbeda-beda dalam memilih sekolah (Fithoni \& Zazili, 2016).

Keputusan penentuan penjurusan peserta didik diambil oleh pihak sekolah dengan mempertimbangkan minat, bakat dan potensi diri peserta didiknya (Ramadhani, Utomo, \& Indriyanti, 2017). Penjurusan ini memiliki tujuan agar kelak di kemudian hari, pelajaran yang akan diberikan kepada siswa menjadi lebih terarah karena sesuai dengan kemampuan dan minatnya (Rahmad, 2018). Tiap peserta didik memiliki minat, bakat, dan potensi yang berbeda (Eliyarti \& Rahayu, 2019a). Hal ini didasari kebutuhan yang berbeda pada tiap individu sebagai manusia. Perbedaan karakteristik dari manusia tidak lain karena perbedaan antar individu memiliki tugas-tugas perkembangan yang harus dipenuhinya serta memiliki kebutuhan yang berbeda satu sama lain (Nurcahyono, Najib, \& Kasim, 2020). Maslow berpendapat bahwa kebutuhan pokok manusia terdiri dari 6 tingkat yang dapat mendorong prilakunya, kebutuhan tersebut antar lain: 1). Kebutuhan Fisik (Physilogical Needs) yang diperlukan untuk mempertahankan hidup, kebutuhan ini disebut juga sebagi kebutuhan primer, seperti Makan, istirahat ,udara yang segar air dll. 2). Kebutuhan akan rasa aman (Safety Needs). seorang akan terganggu pada situasi yang kacau dan ia mudah menarik diri dalam situasi yang membahayakan. 3). Kebutuhan untuk mencintai dan dicintai (Love Needs) merupakan dorongan dan kehausan baginya untuk mendapatkan tempat dalam suatu kelompok ia memperoleh kehangatan perasan dalam hubungan dengan masyarakat lain secara umum. 4). Kebutuhan akan harga diri (Esteem Needs). Menuntut pengakuan individu sebagai pribadi yang bernilai. 5). Kebutuhan akan aktualisasi diri (Self actualization). Memberikan dorongan kepada individu untuk mengembangkan seluruh potensi dalam dirinya. 6). Kebutuhan untuk mengetahui dan mengerti (Desire to know and to understand). Tampak pada individu yang cenderung untuk mensistematisasikan segalnya, menganalisis, mengorganisasi, dan mencari hubunganya dalam kesatuan yang utuh (Zulfa, 2018).

Konsep keterampilan dan kemampuan yang akan dimiliki oleh siswa akan tercermin dalam suatu standar yang ditetapkan oleh pemerintah pusat dan disebut sebagai standar kompetensi lulusan (Coffey \& Gibbs, 2001). Standar yang dibuat dan dirancang ini merupakan acuan minimal yang harus dikuasai oleh setiap siswa untuk lulus dan dapat melanjutkan ke jenjang yang lebih tinggi (Kline, 2005). Pada dasarnya setiap keterampilan harus diukur dengan baik agar kualitas lulusan nantinya menjadi sempurna (Awang, 2011). Setiap standar kompetensi lulusan akan berbeda-beda pada setiap jenjang kelas (Marsh, Tourón, \& Wheeler, 2005). Begitu juga untuk penempatan siswa pada jenjang tertentu. Pada jenjang sekolah menengah, siswa akan ditempatkan sesuai dengan bakat, minat dan kemampuannya yang dapat diukur dalam hasil belajar pada jenjang kelas sebelumnya (Ong, 2006).

Memilih jurusan pada dasarnya merupakan sebuah proses yang sudah dimulai sejak masa anak-anak. Kesempatan, stimulasi, pengalaman apa saja yang diberikan pada anak sejak kecil secara optimum dan konsisten, itu akan menjadi bekal, modal dan fondasi minat dan bakatnya. Makin banyak dan luas exposurenya, makin anak tahu banyak tentang dirinya, tapi makin sedikit exposure nya, makin sedikit juga pengetahuan anak tentang dirinya. Menyadari bahwa jurusan yang dipilih hanya merupakan salah satu anak tangga awal dari dari proses pencapaian karir. Jurusan yang dipilih sebaiknya sesuai dengan kemampuan dan minat siswa yang bersangkutan. Jika seorang siswa memilih jurusan sesuai dengan kemampuan dan minatnya, maka dirinya akan mampu bertahan dalam menghadapi kesulitan-kesulitan selama masa sekolah/kuliah, namun jika dirinya tidak memiliki kemampuan dan minat dalam jurusan yang dipilih, bisa mempengaruhi motivasi belajar (Hasanah, Nurcahyo, \& Santony, 2018). Setiap siswa yang memilih jurusan dilatar belakangi oleh berbagai faktor, dan memiliki pertimbangan yang berbeda-beda, namun ada beberapa faktor dominan 
4086 Deskripsi Sistem Divisi Jurusan Antara Sekolah Indonesia dan Sekolah Menengah Kebangsaan Malaysia-Zakirman, Wienda Gusta, Chichi Rahayu

DOI: https://doi.org/10.31004/edukatif.v3i6.1231

yang akan mempengaruhi siswa dalam memilih jurusan. Secara garis besar terdapat dua faktor yang mempengaruhi siswa dalam memilih jurusan pendidikan lanjutan yaitu faktor intenal (dalam diri) dan faktor eksternal (luar diri). Faktor dalam diri yaitu karakteristik kepribadian (Zola, N., Ilyas \& Yusri, 2017) yang meliputi minat dan motivasi internal (Fitri, E., Ifdil \& Neviyarni, 2016) sedangkan faktor luar diri adalah bimbingan orang tua dan kelompok teman sebaya (Nelissa, Astuti, \& Martunis, 2018).

Motivasi merupakan salah satu faktor yang berpengaruh cukup besar dalam pemilihan jurusan siswa. Motivasi merupakan suatu proses untuk menggalakkan sesuatu tingkah laku supaya dapat mencapai matlumatmatlumat yang tertentu. Gollwitzer dan Oettingen, berpendapat bahwa motivasi adalah apa yang menggerakan manusia untuk melakukan sesuatu (Gollwitzer \& Oettingen, 2015). Motivasi adalah keinginan yang diarahkan menuju stimulus positif atau jauh dari yang negatif serta diaktifkan dan sempurna (Zakirman, 2017). Motivasi mengandung tiga komponen pokok, yaitu menggerakan, mengarahkan, dan menopang tingkah laku manusia yaitu (a)Menggerakan berarti menimbulkan kekuatan pada individu, memimpin seseorang untuk bertindak dengan cara tertentu.Misalnya kekuatan dalam hal ingatan, respon-respon efektif, dan kecenderungan mendapatkan kesenangan, (b) Mengarahkan atau menyalurkan tingkahlaku. Dengan demikian ia menyediakan suatu orientasi tujuan. Tingkah laku individu diarahkan terhadap sesuatu, (c)Untuk menjaga atau menopang tingkah laku, lingkungan sekitar harus menguatkan intensitas dan arah dorongan-dorongan dan kekuatankekuatan (Eliyarti \& Rahayu, 2019b).

Sistem pendidikan di Malaysia diatur oleh Kementerian Pendidikan Malaysia (KPM). Pendidikan formal yang ada di malaysia dimulai dari Pra-sekolah, Pendidikan Rendah, Pendidikan Menengah, Pendidikan Pra-Universiti dan Pengajian Tinggi. Pendidikan merupakan tanggungjawab pemerintah federal. Sistem pendidikan nasional meliputi pendidikan prasekolah hingga perguruan tinggi. Pada tahun 2004 pendidikan prasekolah, dasar dan menengah berada dibawah yurisdiksi Kementrian Pendidikan (the Ministry of Education). Sedangkan pendidikan tinggi merupakan tanggungjawab Kementerian Pendidikan Tinggi (the Ministry of Higher Education). Semua bentuk penyelenggaraan pendidikan didasarkan pada visi dan misi. Adapaun visi dan misi utama pemerintahan Malaysia adalah menjadikan negerinya sebagai pusat pendidikan berkualitas dan siap bersaing dangan lembaga pendidikan tinggi di negara lain (Putra, 2017).

Jika dibandingkan, dengan negara terdekat seperti Malaysia, Indonesia memiliki karakter dan arah konsep pendidikan yang berbeda dengan pendidikan di Malaysia. Perbedaan konsep ini dapat tercermin dari bagaimana manajemen dan manajemen pendidikan (Ghafar, Rahim, H, Sihes, \& Harun, 2010). Hal paling sederhana dapat dilihat pada bagaimana pengelolaan divisi departemen di sekolah-sekolah berlaku di Negara Malaysia. Seharusnya pembagian jurusan ini dapat dilakukan dengan baik dan dapat menampung mahasiswa sesuai minat, bakat dan kemampuannya.

Masalah yang paling mencolok di Indonesia dan paling sering ditemukan dalam banyak kasus adalah persepsi dan pemikiran di masyarakat bahwa jurusan terbaik adalah ilmu alam. Kondisi ini mengakibatkan sebagian besar orang tua berlomba-lomba untuk masuk dan memaksa anaknya masuk jurusan mini science. Pemikiran seperti ini adalah konsep yang salah dan perlu diluruskan. Jika kondisi ini dibiarkan berlarut-larut, maka akan terjadi ketimpangan berupa ketidaksesuaian bakat, minat dan kemampuan anak dengan proses pendidikan yang dijalaninya. Dampak langsung dari kondisi ini adalah siswa akan memiliki motivasi belajar yang rendah dan turut memperburuk keadaan sehingga hasil belajarnya akan menurun.

Jika dibandingkan, kita dapat membandingkan bagaimana pengelolaan divisi departemen di sekolah menengah dengan negara tetangga yaitu Malaysia. Berdasarkan observasi yang telah dilakukan, peneliti dapat menyimpulkan bahwa banyak hal positif yang dapat diambil dari bagaimana pengelolaan sistem distribusi jurusan pada tingkat sekolah menengah di Malaysia. Oleh karena itu peneliti tertarik untuk menulis artikel yang berkaitan dengan perbandingan sistem distribusi departemen antara sekolah Indonesia dan Malaysia. 
4087 Deskripsi Sistem Divisi Jurusan Antara Sekolah Indonesia dan Sekolah Menengah Kebangsaan Malaysia-Zakirman, Wienda Gusta, Chichi Rahayu

DOI: https://doi.org/10.31004/edukatif.v3i6.1231

\section{METODE PENELITIAN}

Jenis penelitian ini adalah deskriptif, dimana peneliti akan melakukan analisis dan membuat perbandingan perbandingan antara sistem distribusi departemen di sekolah menengah di Indonesia dan Malaysia. Instrumen penelitian yang digunakan adalah lembar observasi dan dokumentasi beberapa dokumen terkait yang relevan dengan tema penelitian. Sekolah yang dijadikan acuan dan sampel dalam penelitian ini adalah beberapa sekolah menengah pertama di wilayah Sumatera Barat dan Sekolah Menengah Kejuruan Dato'Onn di Kuala Lumpur, Malaysia. Kesimpulan diambil berdasarkan analisis data observasi dan dokumen terkait yang relevan dengan tema penelitian.

\section{HASIL DAN PEMBAHASAN PENELITIAN}

Malaysia dan Indonesia merupakan dua negara yang memiliki rumpun yang sama, wilayah yang berdekatan, bahasa yang hampir sama, serta berbagai budaya yang juga hampir sama. Berdasarkan kesamaankesamaan tersebut terjalinlah hubungan diplomasi dua negara yang harmonis. Mengenai bidang pendidikan, kedua negara ini sama-sama memiliki perhatian besar dalam bidang ini. Pendidikan di sekolah diberikan sejak usia dini (paud) hingga jenjang pendidikan tinggi.

Pembagian jurusan di tingkat sekolah menengah merupakan proses vital yang tidak boleh disalahartikan. Pada tahap ini merupakan tingkat awal bagi siswa untuk memulai langkahnya menuju masa depan. Oleh karena itu dalam pembagian jurusan bagi mahasiswa harus benar-benar memperhatikan segala aspek yang tentunya akan mempengaruhi pertimbangan dalam penempatan mahasiswa pada jurusan tertentu.

Secara umum pembahasan dalam penelitian ini terbagi menjadi dua kategori utama, yaitu:

\section{Sistem distribusi jurusan di sekolah menengah di Indonesia}

Pendidikan di Indonesia bertumpu pada kurikulum yang digunakan. Kurikulum dipahami sebagai seperangkat rencana dan pengaturan mengenai tujuan, isi, dan bahan pelajaran serta cara yang digunakan sebagai pedoman penyelenggaraan kegiatan pembelajaran untuk mencapai tujuan pendidikan tertentu. Kurikulum dipahami sebagai seperangkat rencana dan pengaturan mengenai tujuan,isi, dan bahan pelajaran serta cara yang digunakan sebagai pedoman penyelenggaraan kegiatan pembelajaran untuk mencapai tujuan pendidikan tertentu (Widyastono, 2012). Kurikulum memiliki empat komponen, yaitu komponen tujuan, isi kurikulum, metode atau strategi pencapaian tujuan dan komponen evaluasi. Dalam sebuah kurikulum memuat suatu tujuan yang ingin dicapai dalam suatu sistem pendidikan. Untuk itu tujuan dalam suatu kurikulum memegang peranan yang sangat penting, karena tujuan mengarahkan semua kegiatan pengajaran dan mewarnai komponen-komponen kurikulum lainnya (Husin, 2013).

Dalam perjalanan sejarah sejak tahun 1945, kurikulum pendidikan nasional telah mengalami perubahan, yaitu pada tahun 1947, 1952, 1964, 1968, 1975, 1984, 1994, 2004, 2006 dan yang sekarang kurikulum 2013 yang walaupun belum merata disatuan pendidikan seluruh Indonesia diterapkan. Perubahan tersebut merupakan konsekuensi logis dari terjadinya perubahan sistem politik, sosial budaya, ekonomi, dan iptek dalam masyarakat berbangsa dan bernegara. Sebab, kurikulum sebagai seperangkat rencana pendidikan perlu dikembangkan secara dinamis sesuai dengan tuntutan dan perubahan yang terjadi di masyarakat. Semua kurikulum nasional dirancang berdasarkan landasan yang sama, yaitu Pancasila dan UUD 1945, perbedaanya pada penekanan pokok dari tujuan pendidikan serta pendekatan dalam merealisasikannya (Afifah, 2015). 
4088 Deskripsi Sistem Divisi Jurusan Antara Sekolah Indonesia dan Sekolah Menengah Kebangsaan Malaysia-Zakirman, Wienda Gusta, Chichi Rahayu

DOI: https://doi.org/10.31004/edukatif.v3i6.1231

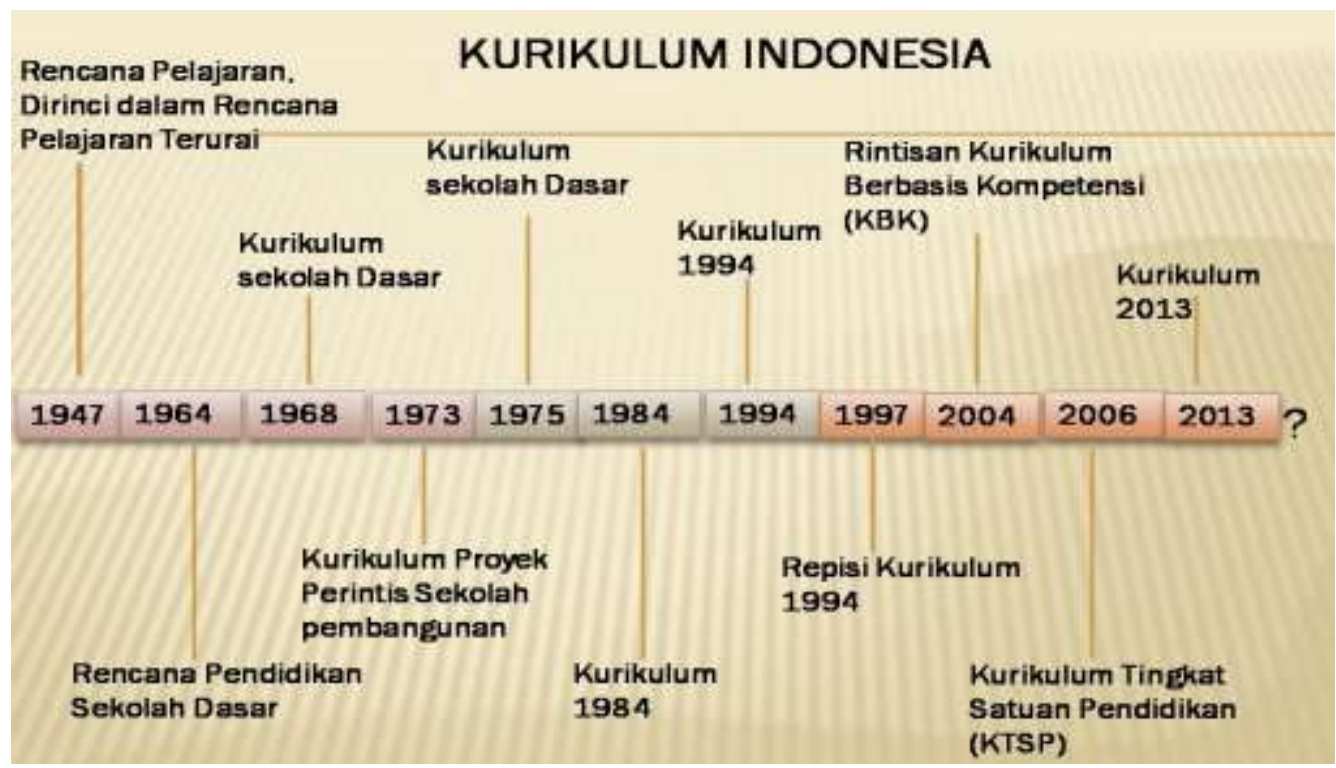

Gambar 1. Skema perubahan kurikulum di Indonesia

Sekolah di Indonesia terbagi menjadi tiga tingkatan, yaitu Sekolah Dasar (SD), Sekolah Menengah Pertama (SMP) dan Sekolah Menengah Atas (SMA). Lama pendidikan tiap jenjang adalah 6 tahun untuk SD, 3 tahun (SMP) dan 3 tahun (SMA). Sistem distribusi jurusan dalam beberapa tahun terakhir telah mengalami beberapa kali reformasi seiring dengan penggantian kurikulum yang berlaku universal. Pada tahun sebelum 2006, sistem pembagian jurusan dimulai pada jenjang kelas tertinggi di SMA, yaitu di kelas XII. Seiring dengan perubahan kurikulum yang ada, pada rentang tahun 2007 hingga 2010, pembagian jurusan di SMA dimulai di kelas XI. Pada perubahan kurikulum yang terakhir yaitu pada kurikulum 2013, pembagian mata kuliah simulasi pada kelas satu di tingkat SMA ada di kelas X. Di Indonesia sendiri, untuk jenjang SMA sendiri setidaknya ada tiga jenis pendidikan. sekolah menengah atas, madrasah agama (keagamaan) dan sekolah menengah kejuruan. Pada dasarnya sistem manajemen departemen untuk ketiga jenis sekolah ini adalah sama, yaitu bersama-sama mulai dari jenjang kelas yang paling rendah hingga jenjang sekolah menengah atas.

Dengan dimulainya pembagian jurusan di SMA pada kelas X, otomatis siswa pada jenjang yang lebih rendah yaitu di kelas VII, VIII dan IX akan memiliki mata pelajaran wajib yang sama pada setiap jenjangnya. Untuk mata pelajaran wajib seperti: Bahasa Indonesia, Bahasa Inggris, Pendidikan Kewarganegaraan, Pendidikan Agama, Seni Budaya, Matematika, Sains (termasuk Fisika, Kimia, Biologi), Pendidikan Sejarah, ada beberapa sekolah yang telah memasukkan materi ekonomi dasar, serta mata pelajaran lokal. konten mata pelajaran seperti memperkenalkan budaya lokal yang dikemas dalam sebuah mata pelajaran. Jika dibandingkan dengan beberapa negara tetangga terdekat di Indonesia, tentunya jumlah mata kuliah wajib di Indonesia cukup besar dibandingkan dengan mata kuliah wajib di negara lain.

Pada jenjang atau jenjang kelas $\mathrm{X}$ di SMA, siswa mulai dibagi menurut jurusan yang tersedia di sekolah. Tentu siswa bisa memilih dari tiga jenis SMA yang ada, mau melanjutkan ke SMA (umum), madrasah aliyah atau sekolah menengah kejuruan. Pada dasarnya sistem pembagian jurusan di SMA pada sekolah-sekolah di Indonesia mengacu pada beberapa aspek yaitu hasil belajar sebelumnya (raport), tes yang diadakan oleh sekolah (umumnya di SMK) dan jika memungkinkan rekomendasi dari hasil tes minat dan bakat. yang telah dilakukan oleh konselor di sekolah.

Di sekolah menengah atas (umum), pembagian jurusan dibagi menjadi tiga kelompok, yaitu kelompok IPA (yaitu yang memiliki kemampuan kuat di bidang matematika dan IPA), kelompok IPS (yaitu yang memiliki kemampuan dan kompetensi yang kuat). bidang sosial/termasuk akuntansi dan ekonomi), dan ilmu bahasa (bagi yang memiliki kemampuan dan keahlian dalam kajian bahasa). Di sekolah menengah kejuruan 
4089 Deskripsi Sistem Divisi Jurusan Antara Sekolah Indonesia dan Sekolah Menengah Kebangsaan Malaysia-Zakirman, Wienda Gusta, Chichi Rahayu

DOI: https://doi.org/10.31004/edukatif.v3i6.1231

terdapat beberapa jurusan yaitu teknik (mesin, listrik, listrik, alat berat, dll), budaya dan seni lokal (batik), akuntansi, pemasaran, administrasi perkantoran dan perhotelan dan pariwisata.

Di sekolah menengah atas (umum), siswa yang telah bergabung dengan jurusan IPA cenderung dapat memahami materi yang berkaitan dengan ilmu-ilmu lain seperti bahasa atau sosial. Siswa dapat mengikuti kursus ini dalam kegiatan pengembangan diri yang umumnya diadakan oleh setiap sekolah pada hari Sabtu. Namun karena sifatnya yang tidak menekankan pada kemampuan penuh, mahasiswa hanya mampu mengambil kelas hanya dalam waktu dua sampai tiga jam belajar. Sistem lintas minat ini merupakan salah satu solusi yang dikembangkan jika ada beberapa siswa yang lebih tertarik pada pengetahuan lintas bidang.

\section{Sistem distribusi departemen di sekolah menengah di Malaysia}

Sistem pendidikan di Malaysia berada di bawah kewenangan Kementrian Pelajaran Malaysia. Di Malaysia, warga negaranya dapat menempuh pendidikan dari sekolah milik kerajaan, sekolah swasta maupun secara individu. Sistem pendidikan yang wajib ditempuh yakni sekolah rendah dan sekolah menengah. Meskipun, bentuk pemerintahan adalah kerajaan, namun kerajaan tak memiliki hak untuk menentukan kurikulum atau cara pengajaran yang harus diterapkan. Semua kewenangan tersebut telah sepenuhnya dilimpahkan kepada Kementrian Pelajaran Malaysia, sementara untuk peraturan pendidikan tinggi diatur oleh Kementrian Pengajian Tinggi Malaysia yang didirikan tahun 2004. Mulai dari tahun 2003 hingga saat ini, Malaysia telah menggunakan Bahasa Inggris sebagai bahasa pengantar dalam mata pelajaran tertentu sepeti sains dan matematika. Sistem pendidikan yang dimiliki sekolah di Malaysia yaitu terkait dengan sistem kebahasaannya mewajibkan bahasa Inggis dan bahasa Melayu, sedangkan di Indonesia hanya mewajibkan bahasa Indonesa saja (Setyani, Zuliyana, Rofitrasari, Amelia, \& Ahsani, 2021).

Jenjang pendidikan di Malaysia terdiri dari beberapa tingkatan. 1) Pendidikan prasekolah atau yang disebut dengan 'tadika' mengajar anak mulai usia 4-6 tahun. Pendidikan ini bukan merupakan pendidikan wajib dalam sistem pendidikan di Malaysia. Sekolah tadika diselenggarakan oleh pemerintah maupun pihak swasta. Selain sekolah tadika, sebagian besar Sekolah Kebangsaan memiliki kelas prasekolah. Kelas khusus ini diperuntukkan untuk anak-anak dari keluarga berpendapatan rendah. 2) Pendidikan rendah di Malaysia ditempuh selama kurun waktu 6 tahun pada usia 7 hingga 12 tahun. Mata pelajaran wajib yang diajarkan ialah Bahasa Melayu dan Bahasa Inggris. Sekolah rendah di Malaysia dibagi dua jenis, yakni: Sekolah Kebangsaan dan Sekolah Jenis Kebangsaan. Untuk kurikulum yang diterapkan di kedua sekolah tersebut sama. Perbedaan yang mencirikan dua sekolah ini ialah bahasa pengantar yang digunakan. Untuk Sekolah Kebangsaan menggunakan Bahasa Melayu sebagai bahasa pengantar, sementara Sekolah Jenis Kebangsaan menggunakan Bahasa Tamil atau Bahasa Mandarin. 3) Sekolah Menengah di Malaysia berlangsung selama 5 tahun. Bahasa yang digunakan sebagai pengantar ialah bahasa Melayu untuk semua mata pelajaran, kecuali Sains dan Matematika. Pada sekolah ini pula, siswa akan diarahkan untuk memasuki jurusan IPA (sains) atau seni (arts). Dalam hal ini siswa diberikan kebebasan untuk memilih sendiri, namun jurusan IPA cenderung lebih populer. Selama menempuh pendidikan menengah, siswa diwajibkan mengikuti aktivitas ekstrakurikuler seperti Kelompok Umum (Uniformed Groups), Penampilan Seni (Performing Arts), Klub dan Kemasyarakatan (Clubs and Societies), Olahraga dan Permainan (Sports and Games). 4) Pendidikan ini merupakan pendidikan yang memberikan kesempatan untuk menempuh studi tingkat 6 di berbagai institusi pendidikan seperti Politeknik. Tingkatan 6 ini terdiri dari tingkatan rend6 ah dan tingkatan 6 atas yang ditempuh selama 2 tahun. Sekolah ini diperuntukkan khusus bagi mereka yang ingin melanjutkan ke pendidikan tinggi di Malaysia. 5) Pengajian tinggi merupakan program pendidikan tinggi yang ada di Malaysia. Pada jenjang ini, kerajaan memberikan subsidi atau beasiswa yang cukup besar di berbagai universitas yang ada di Malaysia. Dalam pelaksanaannya, pengajian tinggi ini diatur oleh Kementrian Pengajian Tinggi Malaysia (Daga, 2020). 
4090 Deskripsi Sistem Divisi Jurusan Antara Sekolah Indonesia dan Sekolah Menengah Kebangsaan Malaysia-Zakirman, Wienda Gusta, Chichi Rahayu

DOI: https://doi.org/10.31004/edukatif.v3i6.1231

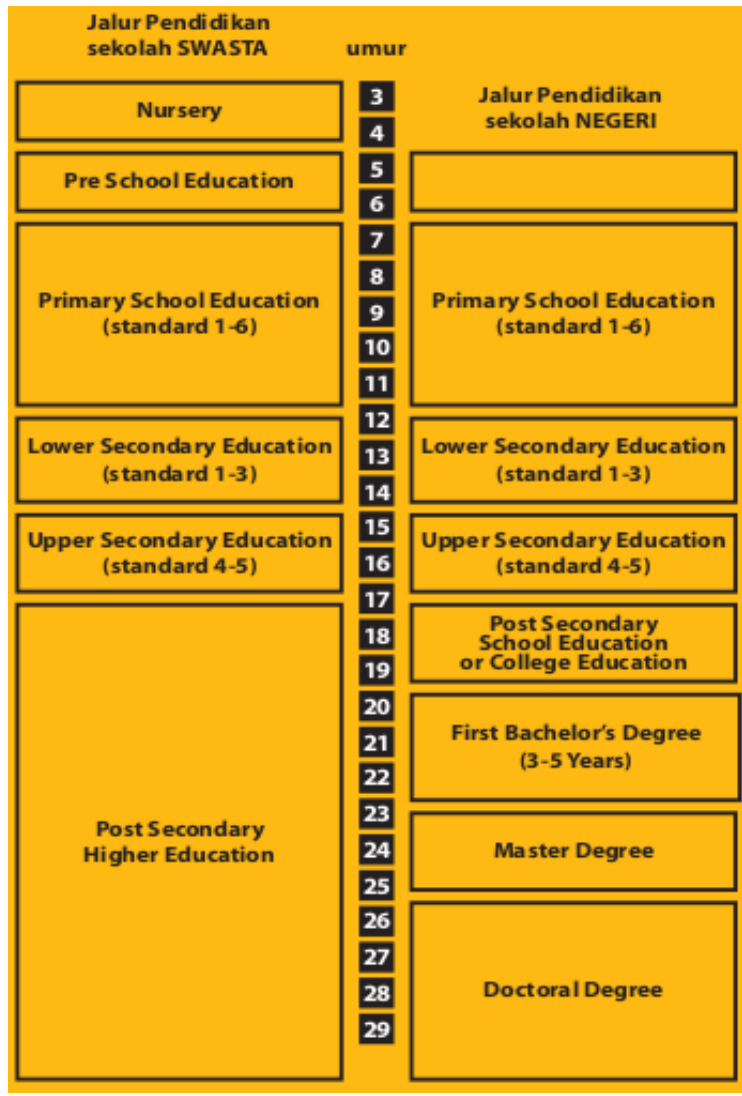

\section{Gambar 2. Deskripsi Jenjang Pendidikan di Malaysia}

Untuk sekolah formal di Malaysia terdiri dari dua jenjang yaitu sekolah rendah atau setingkat SD yang ditempuh dengan masa pendidikan 6 tahun dan SMA kerajaan yang ditempuh selama 5 tahun. SMA kerajaan di Malaysia jika dihubungkan dengan jenjang di Indonesia, merupakan gabungan dari SMP dan SMA. Pembagian jurusan di Royal High School dimulai di kelas 4, atau tahun keempat dalam pembelajaran. Ini berarti bahwa siswa di sekolah menengah kerajaan di Malaysia, di kelas 1 sampai 3, mengikuti mata pelajaran dasar yang sama. Mata pelajaran wajib ini disebut sebagai "sijil" yang terdiri dari 6 mata pelajaran wajib yaitu matematika, IPA, pendidikan sejarah, pendidikan agama, IPS dan pendidikan kewarganegaraan. Bahasa pengantar dalam pembelajaran di Malaysia adalah Bahasa Melayu dan Bahasa Inggris.

Sistem pembagian jurusan di kelas 4 didasarkan pada beberapa pertimbangan, antara lain: hasil belajar, psikometri (respon konselor). Bagi mahasiswa yang akan mengikuti prodi IPA memiliki kriteria matematis dan keilmuan yang menonjol dibandingkan mata kuliah lainnya, serta mendapatkan rekomendasi dari pembimbing agar layak dan mampu melanjutkan pendidikan di prodi IPA.

Di satu sisi, ada beberapa kebijakan yang fleksibel. Artinya mahasiswa yang telah bergabung dengan jurusan tertentu masih diperbolehkan untuk mengembangkan ilmu dan keahlian di bidang lain dengan mengambil mata kuliah lintas minat. Dalam beberapa tahun terakhir, setiap siswa dapat memilih maksimal 21 mata pelajaran, namun karena beberapa kendala di lapangan, beban dibatasi maksimal 18 mata pelajaran.

Di Malaysia, jika siswa tertarik untuk melanjutkan pendidikan ke tingkat kejuruan, pada akhir kelas 3 di sekolah menengah kerajaan, siswa dapat membuat surat lamaran dan menyerahkan dokumen untuk pindah dan melanjutkan pendidikan di sekolah menengah kejuruan. Namun dalam praktiknya, ada beberapa sekolah yang juga memfasilitasi siswa untuk menimba ilmu dan wawasan seperti pendidikan di tingkat SMK.

Pada dasarnya sekolah di Malaysia dan Indonesia tidak jauh berbeda. Perbedaan yang menonjol dari pendidikan kedua negara tersebut pada nama jenjang kedua negara. Tingkatan jenjang pendidikan juga berbeda contohnya ada pada jenjang sekolah menengah dimana sekolah menengah Malaysia ditempuh dalam 
4091 Deskripsi Sistem Divisi Jurusan Antara Sekolah Indonesia dan Sekolah Menengah Kebangsaan Malaysia-Zakirman, Wienda Gusta, Chichi Rahayu

DOI: https://doi.org/10.31004/edukatif.v3i6.1231

jenjang waktu 5 tahun sedangkan di Indonesia 6 tahun (Putra, 2017). Negara Malaysia cenderung lebih maju di bidang pendidikan karena kurikulum yang dipakai baku dan tidak sering ada pergantian kurikulum. Berbeda dengan negara Indonesia yang sering terjadi pergantian kebijakan serta kurikulum sehingga pelaksana teknis di Indonesia lambat untuk berkembang. Alasan lain yang berpengaruh dalam kemajuan pendidikan di kedua negara adalah bekas dari negara yang berbeda. Hal ini sedikitnya mempengaruhi sistem pendidikan di kedua negara.

\section{KESIMPULAN}

Kesimpulan dari hasil penelitian ini antara lain perbedaan sistem pembagian jurusan dengan perbedaan yang mencolok yaitu di Indonesia sekolah dapat mengelompokkan siswa berdasarkan jurusan pada jenjang kelas X, sedangkan di Malaysia pengelompokan jurusan dimulai pada kelas 4 pada jenjang sekolah menengah. Selain itu, perbedaan dasar kurikulum yang harus ditempuh siswa juga dapat terlihat jelas dan berbeda secara signifikan.

\section{DAFTAR PUSTAKA}

Afifah, N. (2015). Problematika Pendidikan di Indonesia (Telaah dari Aspek Pembelajaran). Jurnal Elementary, 1(1), 41-47.

Andayani, E. S. (2012). Analisis Sistem Pendidikan Indonesia Dalam Kaitannya Dengan Isu-isu Lokal, Regional dan Global. Seminar Bidang Pendidikan 2012, 16-17.

Arokiasamy, A. R. A. (2012). Globalization and Higher Education: A Malaysian Perspective. International Journal of Advances in Management and Economics, 1(13), 10-16.

Awang, Z. (2011). A handbook on SEM: Structural Equation Modelling, 2nd Edition. New York: Tylor \& Francis Group.

Coffey, M., \& Gibbs, G. (2001). The Evaluation of the Student Evaluation of Educational Quality Questionnaire (SEEQ) in UK higher education. Assessment \& Evaluation in Higher Education, 26(1), 37-41. Retrieved from http://dx.doi.org/10.1080/02602930020022318

Daga, A. T. (2020). Perbandingan Pendidikan Karakter Dalam Kurikulum Sekolah Dasar di Malaysia, India dan Indonesia. Jurnal Edukasi Sumba, 4(1), 23-30.

Eliyarti, E., \& Rahayu, C. (2019a). Deskripsi Efektivitas Kegiatan Praktikum Dalam Perkuliahan Kimia Dasar Mahasiswa Teknik. Edu Sains : Jurnal Pendidikan Sains \& Matematika, 7(2), 51-60.

Eliyarti, E., \& Rahayu, C. (2019b). Tinjauan Motivasi Berprestasi Mahasiswa Teknik Dalam Perkuliahan Kimia Dasar. Jurnal Pendidikan Glasser, 3(2), 196-204.

Eliyarti, E., Rahayu, C., \& Zakirman, Z. (2020). Tinjauan Kontribusi Google Classroom Dalam Mendukung Perkuliahan Kimia Dasar. Jurnal Pendidikan Kimia Indonesia, 4(1), 32-39.

Fithoni, A., \& Zazili, Z. (2016). Pengaruh Jurusan , Biaya dan Kualitas terhadap Keputusan Siswa Untuk Masuk SMK Negeri 2 Batanghari. Eksis: Jurnal Ilmiah Ekonomi Dan Bisnis, 10(1), 7-15.

Fitri, E., Ifdil, I., \& Neviyarni, S. (2016). Efektivitas Layanan Informasi dengan Menggunakan Metode Blended Learning untuk Meningkatkan Motivasi Belajar. Jurnal Psikologi Pendidikan Dan Konseling: Jurnal Kajian Psikologi Pendidikan Dan Bimbingan Konseling, 2(2), 84-92.

Ghafar, M. N., Rahim, H, A., Sihes, A. J., \& Harun, A. (2010). Integrated Curriculum Concepts in Malaysia: Knowledge and Application Differentiation. European Journal of Social Sciences, 19(2), 208.

Gollwitzer, P. M., \& Oettingen, G. (2015). Motivation: History of the Concept. International Encyclopedia of the Social \& Behavioral Sciences: Second Edition, 15(2), 390-395. https://doi.org/10.1016/B978-0-08097086-8.03079-8 
4092 Deskripsi Sistem Divisi Jurusan Antara Sekolah Indonesia dan Sekolah Menengah Kebangsaan Malaysia-Zakirman, Wienda Gusta, Chichi Rahayu

DOI: https://doi.org/10.31004/edukatif.v3i6.1231

Hasanah, U., Nurcahyo, G. W., \& Santony, J. (2018). Indikator Pemilihan Jurusan Pada SMK Nusantara Menggunakan Metode SAW. Jurnal Mantik Penusa, 22(1), 39-44.

Hayurika, T. L., \& Arief, S. (2020). Analisis Faktor-Faktor yang Mempengaruhi Minat Siswa Dalam Pengambilan Keputusan Memilih Jurusan Akuntansi Kelas X di SMKN 1 Demak. Jurnal Pendidikan Ekonomi Dinamika Pendidikan, X(June 2015), 88-103. https://doi.org/10.15294/dp.v10i1.5097

Husin, A. (2013). Telaah Sistem Pendidikan Nasional dari Perspektif Pendidikan Pembebasan. Seminar Nasional Pendidikan 2013, 37-47.

Kline, R. B. (2005). Principles and Practice of Structural Equation Modeling. Nature, 156. Retrieved from http://dx.doi.org/10.1038/156278a0

Marsh, H. W., Tourón, J., \& Wheeler, B. (2005). Students' Evaluations of University Instructors: The Applicability of American Instruments in A Spanish Setting. Teaching and Teacher Education, 1(2), 123-138. Retrieved from http://dx.doi.org/10.1016/0742-051X(85)90011-3

Munirah, M. (2015). Sistem Pendidikan di Indonesia: Antara Keinginan dan Realita. Jurnal Auladuna, 2(2), 233-245.

Nelissa, Z., Astuti, S., \& Martunis, M. (2018). Identifikasi Faktor yang Mempengaruhi Siswa dalam Proses Pemilihan Jurusan Pendidikan Lanjutan ( Studi pada Siswa Kelas XI SMA Negeri 5 Banda Aceh ). Jurnal Penelitian Pendidikan Indonesia, 4(2007), 78-83.

Neville, W. (2018). Restructuring Tertiary Education in Malaysia: The Nature and Implications of Policy Changes'. Higher Education Policy, 11, 257-279.

Nurcahyono, D., Najib, A., \& Kasim, W. (2020). Perancangan Aplikasi Pemilihan Jurusan Pada SMK Negeri 7 Samarinda Online Dengan Topsis. Jurnal Sains Terapan Teknologi Informasi, 2, 26-30.

Ong, E. T. (2006). The Malaysian Smart Schools Project: An Innovation to Address Sustainability. 10th UNESCO-APEID International Conference on Education "Learning Together for Tomorrow: Education for Sustainable Development. Bangkok.

Putra, A. (2017). Mengkaji \& Membandingkan Kurikulum 7 Negara. Retrieved from https://osf.io/preprints/inarxiv/vdz32

Putranto, E. A., Salamah, U., \& Wiharto. (2012). Sistem Pendukung Keputusan Penjurusan Siswa Kelas X SMA Negeri 2 dengan Metode Fuzzy C -Means dengan Penggunaan Daya Dukung Minat. Jurnal ITSMART, 1(2), 68-73.

Rahmad, U. (2018). Analisis Referensi Siswa Sekolah Menengah Kejuruan Dalam Memilih Program Studi di Perguruan Tinggi. Jurnal Manajemen Dan Supervisi Pendidikan, 2, 147-152.

Rahmayu, M., \& Serli, R. K. (2018). Sistem Pendukung Keputusan Pemilihan Jurusan Pada SMK Putra Nusantara Jakarta Menggunakan Metode Analytical Hierarchy Process (AHP). Jurnal Simetris, 9(1), 551-564.

Ramadhani, D. G., Utomo, S. B., \& Indriyanti, N. Y. (2017). Students Behavioral Learning Patterns in Environmental Chemistry Blended Course: An Analysis toward 21 st Century Graduates. The 2nd International Conference on Science, Mathematics, Environment, and Education, 1-7.

Rusdiansyah, R. (2017). Analisis Keputusan Menentukan Jurusan Pada Sekolah Menengah Kejuruan Dengan Metode Simple Additive Weighting. Jurnal Techno Nusa Mandiri, XIV(1), 49-56.

Setyani, S., Zuliyana, F., Rofitrasari, R., Amelia, N., \& Ahsani, E. L. F. (2021). Analisis Sistem Pendidikan di Sekolah Indonesia Kuala Lumpur (SIKL): Perspektif Guru. Jurnal PGSD : Jurnal Ilmiah Pendidikan Guru Sekolah Dasar, 14(1), 70-79.

Widyastono, H. (2012). Muatan Pendidikan Holistik Dalam Kurikulum Pendidikan Dasar dan Menengah. Jurnal Pendidikan Dan Kebudayaan, 18(4), 467-476.

Zakirman, Z. (2017). Pengelompokan Gaya Belajar Mahasiswa Menurut Teori Honey Mumford Berdasarkan 
4093 Deskripsi Sistem Divisi Jurusan Antara Sekolah Indonesia dan Sekolah Menengah Kebangsaan Malaysia-Zakirman, Wienda Gusta, Chichi Rahayu

DOI: https://doi.org/10.31004/edukatif.v3i6.1231

Intensitas Kunjungan Pustaka. RISTEKDIK; Jurnal Bimbingan Dan Konseling, 4(1), 1-6.

Zola, N., Ilyas, A., \& Yusri, Y. (2017). Karakteristik Anak Bungsu. Jurnal Konseling Dan Pendidikan, 5(3), $109-114$.

Zulfa, Z. (2018). Profil Penasehat Akademis (PA) Dalam Pelayanan Konseling Karier di Perguruan Tinggi. Jurnal Counseling Care, 2, 28-41. 